\title{
Energy Expenditures for Activities of Daily Living in Korean Young Adults: A Preliminary Study
}

\author{
Kye Hee Cho, $\mathrm{MD}^{1,2}$, Woojin Song, $\mathrm{MS}^{2}$, Jungsoo Kim, MPH${ }^{2}$, Eun Ji Jung, MS' \\ Joonyoung Jang, $\mathrm{MD}^{1}$, Sang Hee Im, MD, $\mathrm{PhD}^{1,2}$, MinYoung Kim, MD, PhD ${ }^{1,2}$ \\ ${ }^{1}$ Department of Rehabilitation Medicine, CHA Bundang Medical Center, CHA University, Seongnam; \\ ${ }^{2}$ Rehabilitation and Regeneration Research Center, CHA University, Seongnam, Korea
}

\begin{abstract}
Objective To investigate the energy expenditure (EE) of Korean young adults based on activities refined to a deskbound lifestyle.

Methods Sixty-four healthy office workers aged between 25 and 46 years participated in this study. EE was expressed as metabolic equivalent of task (MET). Participants were evaluated in terms of their EE during physical activities of sleeping $(\mathrm{n}=22)$, typing $(\mathrm{n}=37)$, folding laundry $(\mathrm{n}=34)$, dishwashing $(\mathrm{n}=32)$, studying $(\mathrm{n}=18)$, mopping ( $\mathrm{n}=35)$, walking $(\mathrm{n}=33)$, stair climbing $(\mathrm{n}=23)$, and running $(\mathrm{n}=29)$. Volume of oxygen consumption was measured by indirect calorimetry $\mathrm{K}^{2} \mathrm{~b}^{2}$ (COSMED). The results were compared to the established Compendium MET.

Results The MET of activities were: sleeping, 1.24 \pm 0.43 ; typing, $1.35 \pm 0.25$; folding laundry, $1.58 \pm 0.51$; dishwashing, $2.20 \pm 0.51$; studying, $2.11 \pm 0.90$; mopping, $2.72 \pm 0.69$; walking at $4 \mathrm{~km} / \mathrm{hr}, 3.48 \pm 0.65$; stair climbing of five stories, $6.18 \pm 1.08$; and running at $8 \mathrm{~km} / \mathrm{hr}, 7.57 \pm 0.57$. The values of typing and mopping were similar to those in the Compendium, whereas those of sleeping, folding laundry, dishwashing, studying, walking, stair climbing and running were different.

Conclusion To our knowledge, this estimation of EE in MET during activities of daily living is the first data of young adults in Korea. These data could be used as a reference to modify the guidelines of physical activities for the age group examined in this study.
\end{abstract}

Keywords Physical exertion, Energy expenditure, Metabolic equivalent, Indirect calorimetry

Received November 2, 2015; Accepted February 11, 2016

Corresponding author: MinYoung Kim

Department of Rehabilitation Medicine, CHA Bundang Medical Center, CHA University, 59 Yatap-ro, Bundang-gu, Seongnam 13496, Korea. Tel: +8231-780-6281, Fax: +82-31-780-6206, E-mail: kmin@cha.ac.kr

ORCID: Kye Hee Cho (http://orcid.org/0000-0003-3818-9403); Woojin Song (http://orcid.org/0000-0002-0190-2319); Jungsoo Kim (http://orcid. org/0000-0002-3190-1165); Eun Ji Jung (http://orcid.org/0000-0002-9987-0529); Jun Young Jang (http://orcid.org/0000-0002-4646-6354); Sang Hee Im (http://orcid.org/0000-0001-5128-5526); MinYoung Kim (http://orcid.org/0000-0001-5481-2985).

@ This is an open-access article distributed under the terms of the Creative Commons Attribution Non-Commercial License (http://creativecommons.org/ licenses/by-nc/4.0) which permits unrestricted noncommercial use, distribution, and reproduction in any medium, provided the original work is properly cited. Copyright $\odot 2016$ by Korean Academy of Rehabilitation Medicine 


\section{INTRODUCTION}

In the milieu of automation and computerization, people are more prone to adopt a sedentary lifestyle that threatens health outcomes [1]. The significance of physical activity (PA) and exercise in reduction of not only cardiovascular risks and overall mortality [2] but also cancer mortality risks [3] has become evident. PA refers to any movement of skeletal muscle that leads to energy expenditure (EE) [4]. The measures of PA are classified into three categories based on: EE or oxygen consumption, heart rate monitoring, and whole-body accelerometry [5]. The EE expressed as a measure of metabolic equivalent of task (MET) is widely used to describe most activities in all range of population [6]. One MET is defined as the amount of oxygen consumed at rest or the resting metabolic rate, and is approximately $3.5 \mathrm{~mL}$ of oxygen per minute per kilogram body weight [7]

To provide EE guidelines, the energy costs of PA have been compiled in the list of gross EE of specified activities in the "1985 Joint Food and Agriculture Organization/ World Health Organization/United Nations University Expert Consultation on Energy and Protein Requirements" [8]. The need for consistency in assigning PA intensity levels in the questionnaires used in epidemiologic studies resulted in multisite studies from 1987 to 1989, supported by the National Heart, Lung, and Blood Institute, leading to development of the Compendium in the United State. In 1993, the "Compendium of Physical Activities" was first published and linked types of PA with the associated EE in MET [9]. The activity intensity level was expressed as multiples of the standard resting energy value of 1 MET. The Compendium has continued to accumulate and categorize published reports of measured energy cost in MET. The latest version of the Compendium was published in 2011 , and about $68 \%$ of catalogued PAs have measured MET values [10].

The Korea Ministry of Health and Welfare established "Activity Guidelines for Koreans" to promote PAs for health in 2013 [11]. However, the guidelines lack baseline reference data and supportive evidence in a Korean population. It was reported that significant racial and ethnic differences might exist in PA [12]. Thus, the types and amounts of PA should be appropriate to the cultural, social and environmental characteristics of the target population [13]. Therefore, it is important to establish the EE of Koreans for developing public health guidelines. This study aimed to estimate the energy consumption of Korean young adults in activities of daily living and to compare the results with the MET values in the Compendium.

\section{MATERIALS AND METHODS}

From May 2014 to December 2015, 64 healthy volunteers of deskbound vocation aged between 25 and 46 years participated (Table 1). Exclusion criteria were a history of cardiovascular, pulmonary, metabolic, musculoskeletal disease or orthopedic surgery. All participants were given detailed information about the process of the study and provided written informed consent before participation. Nine activities of daily living, including

Table 1. Characteristics of participants according to activity

\begin{tabular}{lllccc}
\hline \multicolumn{1}{c}{ Activity } & N (M:F) & Age $(\mathbf{y r})$ & BMI $\left(\mathbf{k g} / \mathbf{m}^{\mathbf{2}}\right)$ & Height $\mathbf{( c m )}$ & Weight $\mathbf{( k g )}$ \\
\hline Sleeping & $22(9: 13)$ & $31.2 \pm 4.9$ & $22.2 \pm 3.7$ & $165.7 \pm 8.2$ & $61.7 \pm 15.3$ \\
\hline Typing & $37(22: 15)$ & $31.2 \pm 5.0$ & $23.2 \pm 3.4$ & $168.6 \pm 7.0$ & $66.3 \pm 12.6$ \\
\hline Folding laundry & $34(21: 13)$ & $32.9 \pm 5.4$ & $23.3 \pm 3.3$ & $168.7 \pm 7.5$ & $66.6 \pm 12.8$ \\
Dishwashing & $32(19: 13)$ & $32.1 \pm 5.0$ & $22.8 \pm 3.7$ & $168.3 \pm 7.3$ & $65.1 \pm 13.7$ \\
\hline Studying & $18(8: 10)$ & $31.7 \pm 5.2$ & $22.5 \pm 4.0$ & $167.4 \pm 7.7$ & $63.9 \pm 15.8$ \\
Mopping & $35(23: 12)$ & $33.1 \pm 5.1$ & $23.3 \pm 3.5$ & $168.8 \pm 7.8$ & $67.0 \pm 13.6$ \\
\hline Walking & $33(23: 10)$ & $33.2 \pm 5.3$ & $23.6 \pm 3.3$ & $170.3 \pm 6.3$ & $68.6 \pm 11.9$ \\
\hline Stair climbing & $23(12: 11)$ & $31.0 \pm 4.9$ & $22.7 \pm 3.6$ & $168.6 \pm 7.9$ & $65.2 \pm 14.9$ \\
\hline Running & $29(20: 9)$ & $33.8 \pm 5.3$ & $23.5 \pm 3.5$ & $169.3 \pm 6.9$ & $67.9 \pm 12.9$ \\
\hline
\end{tabular}

Values are presented as mean \pm standard deviation.

$\mathrm{N}$, number of participants; M, male; F, female; BMI, body mass index. 
domestic chores of a single household, deskbound occupation activities and prevalent activities of various intensities, were selected to reflect the lifestyle of Korean individuals of this age group. Participants were advised to maintain their usual dietary intake and the level of physical activities on the day of activity performance. They were instructed to perform the activity as they would do at home. The number of activities performed per individual differed depending on the time available to the volunteer. The activities of daily living were assessed in a laboratory furnished to mimic a household (e.g., dining tables and sink). The instructions provided to participants were as follows.

(1) Sleeping: Sleep sideways on a bed for 10 minutes.

(2) Typing: Sit on a chair with a straight back. Use dual monitors, type 2,000 words onto one monitor exactly as they appear on the other monitor.

(3) Folding laundry: Sit up straight. Fold the following clothes on the table; one round neck T-shirt, one dress shirt, two pants, four socks, and two towels. Then, organize them in the drawer.

(4) Dishwashing: Clear the dishes; three or four plates, two cups, two spoons and two chopsticks from the table and wash the dishes while standing. Then, put them away to dry. Use of various types of dishtowels and sponges is allowed.

(5) Studying: Sit up in a chair, read a non-technical book and take notes if needed. The content of the text must be understood.

(6) Mopping: Prepare a bucket filled with water and a mop. Then, clean up a $3.3 \mathrm{~m}^{2}$ floor using the mop in a standing position for 5 minutes.

(7) Walking: Walk on a treadmill without any inclination at a speed of $4 \mathrm{~km} / \mathrm{h}$ at a consistent step width for 10 minutes.

(8) Stair climbing: Walk up the stairway from the ground floor to the fifth floor (stair riser height, $10 \mathrm{~cm}$ ). Holding the side rail is allowed. Activity should be stopped in case of severe fatigue or rapidly increasing heart rate.

(9) Running: Run on a treadmill without any inclination at a speed of $8 \mathrm{~km} / \mathrm{h}$ for 5 minutes.

PAs that cover occupation and household activities were selected from list of activities provided by the Compendium [10]. The details of each activity were modified to reflect Korean young household in terms of the number of laundry items folded and dishes washed based on the amounts in a single household. The keyboard typing activity was selected as it is involved in most deskbound activities. The floor cleaning pattern has changed from scrubbing on hands and knees to mopping while standing; thus, the latter was used in this study. In addition, physical activities of locomotion including walking, stair climbing and running were selected. For participants with a deskbound occupation, walking was included as the most common form of exercise of moderate intensity, and stair climbing and running as activities of vigorous intensity $[14,15]$. The walking speed was $4 \mathrm{~km} / \mathrm{h}$, which was within the normal walking speed of 60 to $100 \mathrm{~m} / \mathrm{min}$ [16]. A treadmill was used to maintain a level surface and rate of movement to standardize the results.

To measure oxygen consumption $\left(\mathrm{VO}_{2}\right)$ during each activity, a portable respiratory gas analyzer, $\mathrm{K} \mathrm{b}^{2}$ (COSMED, Rome, Italy) was used. The validity of $\mathrm{K} \mathrm{b}^{2}$ as indirect calorimetry for analyzing oxygen consumption during submaximal exercise has been established as similar to traditional, stationary gas-exchange systems [17]. The $\mathrm{K}_{4} \mathrm{~b}^{2}$ is composed of a rubber mask, a turbine that collects gas, and a mesh headpiece that continuously measures cardiopulmonary function. It is the first portable system for pulmonary gas exchange measurement with true breath-by-breath analysis [18]. Physiologic components-including the metabolic rate, oxygen consumption, carbon dioxide exhaustion, ventilation rate, maximum pulse rate, and respiratory rate during exercise or rest-were measured.

On the first visit to the laboratory, anthropometric data including the weight, height and body mass index (BMI) of each participant were collected. Participants performed the activity when their general condition was agreeable. The $\mathrm{K}_{4} \mathrm{~b}^{2}$ was calibrated for 10 minutes before initiation of each assessment while the participant got accustomed to the laboratory. Then, $\mathrm{K} \mathrm{b}^{2}$ was mounted to each individual using straps and the mask was adjusted to fit the patient correctly (Fig. 1). To allow adaptation to the equipment, the participant was instructed regarding the details of the activity whilst wearing the equipment. Participants equipped with $\mathrm{K}_{4} \mathrm{~b}^{2}$ performed two or three activities consecutively in a single day. Each activity lasted about 5 to 10 minutes and there was a 10-minute recess between each activity to enable calibration of the $\mathrm{K}_{4} \mathrm{~b}^{2}$. The calibration process consisted of four steps: room air calibration, reference gas calibration, delay cali- 

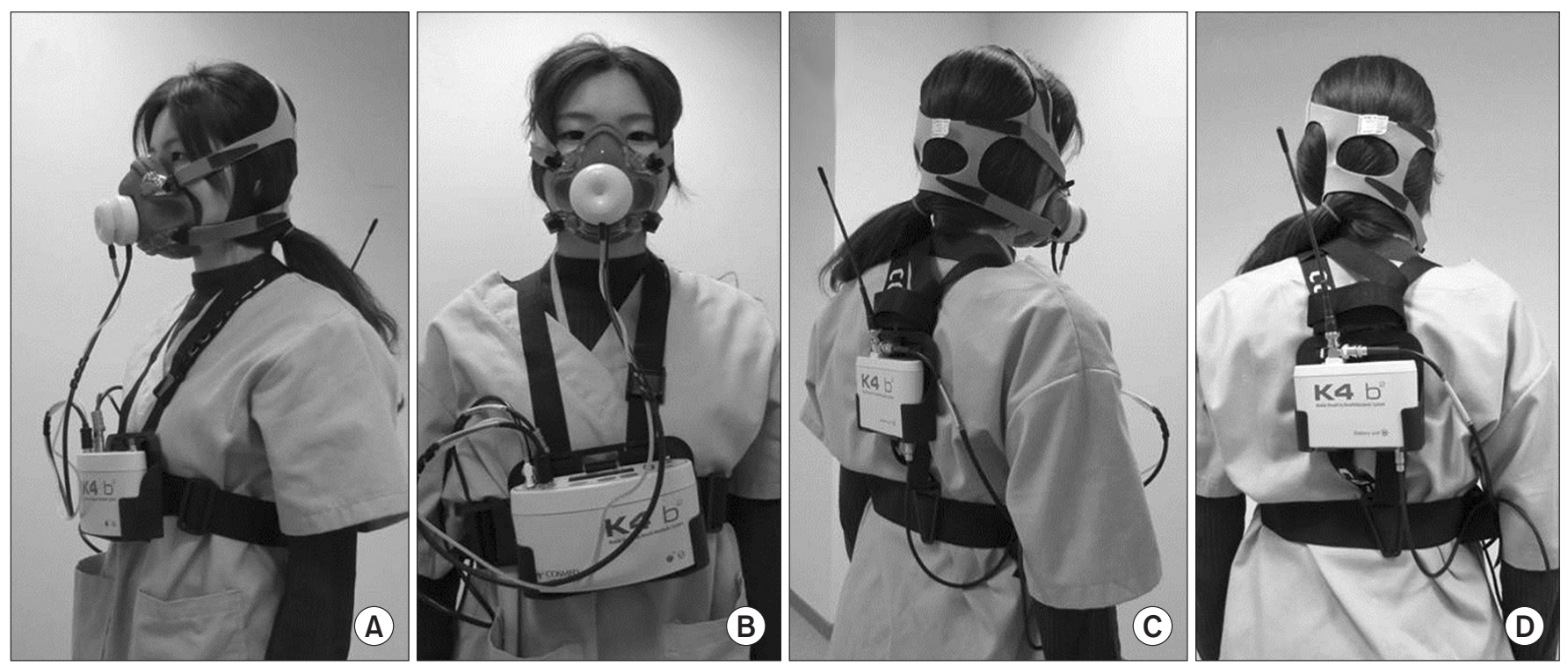

Fig. 1. The portable gas exchange analyzer, $K 4 \mathrm{~b}^{2}$ (COSMED, Rome, Italy) mounted on a participant, viewed from the left (A), front (B) right back (C), and back (D), used to measure oxygen uptake.

bration, and turbine calibration. Room air calibration involved updating of the $\mathrm{CO}_{2}$ analyzer baseline and the $\mathrm{O}_{2}$ analyzer gain in accordance with the atmospheric values. Then, a gas mixture of $16 \%$ oxygen, $5 \%$ carbohydrate, and $79 \%$ nitrogen was used for reference gas calibration. The delay calibration of the flowmeter consisted of inhalation and exhalation into the mask to adjust the time lag between the flowmeter and the gas analyzer. The turbine assembly was dismantled and reconstructed for volume calibration according to the manufacturer's guidelines. The portable nature of the calorimeter enabled measurements regardless of location.

For statistical analysis, SPSS ver. 21.0 (SPSS IBM, Armonk, NY, USA) was used. The EE in MET for each activity was calculated by dividing the measured $\mathrm{VO}_{2}$ or work metabolic rate by 3.5 .

$$
\text { MET }=\frac{\text { Work metabolic rate or } \mathrm{VO}_{2}\left(\mathrm{~mL} \mathrm{O}_{2} * \mathrm{~kg}^{-1} * \mathrm{~min}^{-1}\right)}{\text { Resting metabolic rate }\left(3.5 \mathrm{~mL} \mathrm{O}_{2} * \mathrm{~kg}^{-1} * \mathrm{~min}^{-1}\right)}
$$

Descriptive statistics was used for analysis of the participants' demographic characteristics. The Pearson correlation coefficient was calculated for the correlations between EE and physiologic traits, including BMI and age. The difference between genders was analyzed by independent t-test. The measured MET of each activity was compared to that in the Compendium 2011 by one sample t-test, and was considered similar if the p-value did not indicate satisfaction of the null hypothesis that the two values were different.

This study was approved by the Institutional Review Board of CHA Bundang Medical Center. The work described was carried out in accordance with the Declaration of Helsinki for experiments involving humans.

\section{RESULTS}

The EE was measured in MET based on the $\mathrm{VO}_{2}$ consumed for each activity. The intraclass correlation coefficient (ICC) of $\mathrm{VO}_{2}$ and $\mathrm{VCO}_{2}$ was 0.988 and 0.989 for running and 0.955 and 0.948 for walking on a treadmill, respectively. The METs of the activities were: sleeping, $1.24 \pm 0.43$; typing, $1.35 \pm 0.25$; folding laundry, $1.58 \pm 0.51$; dishwashing, 2.20 \pm 0.51 ; studying, $2.11 \pm 0.90$; mopping, $2.72 \pm 0.69$; walking, $3.48 \pm 0.65$; stair climbing $6.18 \pm 1.08$; and running, $7.57 \pm 0.57$. The EE in kilocalories and the level of intensity for each activity is shown in Table 2 . There was no difference in MET between genders. The majority of the MET values measured in this study differed from those in the Compendium $(\mathrm{p}<0.01)$. However, the MET values of typing and mopping were similar to those in the Compendium (Table 3).

According to correlation analyses, the EE for stair climbing was correlated with height $(\mathrm{r}=0.502, \mathrm{p}<0.05)$ and weight $(r=0.455, p<0.05)$; i.e., those with lower height 
Table 2. EE in MET and kilocalories according to activity level

\begin{tabular}{lccc}
\hline \multicolumn{1}{c}{ Activity } & EE in MET & EE in calorie (kcal/min) & Level of activity [7] \\
\hline Sleeping $(\mathrm{n}=22)$ & $1.24 \pm 0.43$ & $1.31 \pm 0.43$ & Light \\
Typing $(\mathrm{n}=37)$ & $1.35 \pm 0.25$ & $1.55 \pm 0.33$ & Light \\
Folding laundry $(\mathrm{n}=34)$ & $1.58 \pm 0.51$ & $1.89 \pm 0.71$ & Light \\
Dishwashing $(\mathrm{n}=32)$ & $2.20 \pm 0.51$ & $2.47 \pm 0.68$ & Light \\
Studying $(\mathrm{n}=18)$ & $2.11 \pm 0.90$ & $2.29 \pm 0.98$ & Light \\
Mopping $(\mathrm{n}=35)$ & $2.72 \pm 0.69$ & $3.15 \pm 0.94$ & Light \\
Walking $(\mathrm{n}=33)$ & $3.48 \pm 0.65$ & $4.14 \pm 0.90$ & Moderate \\
Stair climbing $(\mathrm{n}=23)$ & $6.18 \pm 1.08$ & $6.93 \pm 1.56$ & Heavy \\
Running $(\mathrm{n}=29)$ & $7.57 \pm 0.57$ & $8.98 \pm 1.86$ & Heavy \\
\hline
\end{tabular}

Values are presented as mean \pm standard deviation.

EE, energy expenditure; MET, metabolic equivalent (light, <3 METs; moderate, 3-6 METs; heavy, >6 METs).

Table 3. EE in MET as measured by indirect calorimetry in comparison to Compendium MET values

\begin{tabular}{|c|c|c|c|c|c|}
\hline \multirow{2}{*}{ Activity } & \multirow{2}{*}{ EE in MET } & \multicolumn{2}{|c|}{ Compendium MET [10] } & \multirow{2}{*}{ Description of Compendium MET [10] } & \multirow{2}{*}{ p-value } \\
\hline & & Value & Range & & \\
\hline Sleeping & $1.24 \pm 0.43$ & 0.95 & $0.94-0.95$ & Sleeping & $0.004^{*}$ \\
\hline Typing & $1.35 \pm 0.25$ & 1.3 & $1.14-1.65$ & Sitting, writing, desk work, typing & 0.27 \\
\hline Folding laundry & $1.58 \pm 0.51$ & 2.0 & $1.5-2.77$ & $\begin{array}{l}\text { Laundry, fold or hang clothes, put cloths } \\
\text { in washer or dryer, packing suitcase, } \\
\text { washing clothes by hand, implied standing, } \\
\text { light effort }\end{array}$ & $<0.001^{* *}$ \\
\hline Dishwashing & $2.20 \pm 0.51$ & 2.5 & $\begin{array}{l}2.14 \pm 0.5 \text { to } \\
2.7 \pm 0.3[15]\end{array}$ & $\begin{array}{l}\text { Wash dishes, clearing dishes from } \\
\text { table, walking, light effort }\end{array}$ & $0.002^{*}$ \\
\hline Studying & $2.11 \pm 0.90$ & 1.3 & $1.28-1.38$ & $\begin{array}{l}\text { Sitting, studying, general, including } \\
\text { reading and/or writing, light effort }\end{array}$ & $0.001^{*}$ \\
\hline Mopping & $2.72 \pm 0.69$ & 2.5 & $2.4-2.6$ & Cleaning, mopping, standing light effort & 0.07 \\
\hline Walking & $3.48 \pm 0.65$ & 3.0 & 2.8 to $3.5 \pm 0.5$ & Walking, $2.5 \mathrm{mph}$, level, firm surface & $<0.001^{* *}$ \\
\hline Stair climbing & $6.18 \pm 1.08$ & $4.0 / 8.0$ & 3.1 to $10.2 \pm 2$ & Stair climbing, slow pace/fast pace & $<0.001^{* *}$ \\
\hline Running & $7.57 \pm 0.57$ & 8.3 & $7.74-9.3$ & Running, $5 \mathrm{mph}$ & $<0.001^{* *}$ \\
\hline
\end{tabular}

Values are presented as mean \pm standard deviation.

$\mathrm{EE}$, energy expenditure; MET, metabolic equivalent; $\mathrm{mph}$, miles per hour; range, range of reference values in the Compendium.

${ }^{*} \mathrm{p}<0.01,{ }^{* *} \mathrm{p}<0.001$ by one sample t-test.

and weight consumed a greater amount of energy for stair climbing. The EE for folding laundry was correlated with BMI ( $\mathrm{r}=0.362, \mathrm{p}=0.035)$, which suggests a higher body mass is associated with greater energy expenditure even for activities of insignificant energy cost (Table 4).

\section{DISCUSSION}

The optimal dosage, duration, frequency, and intensity of PA are important for formulation of effective PA guide- lines [14]. Thus, establishment of reference EE values for various activities is vital. The Compendium MET is the standard reference for the EE values of most activities. However, as it was designed as an activity classification system rather than for precise energy cost guidance [15], further stratification is needed for specific application onto various range of age, gender, physical state, ethnicity, and culture. As these factors may influence the EE, it is important to determine the MET values for activities representative of various cultural backgrounds. In this 
Table 4. Pearson correlation coefficient between BMI and age for activities of EE in MET

\begin{tabular}{lcccc}
\hline \multicolumn{1}{c}{ Activity } & Age $(\mathbf{y r})$ & Height $\mathbf{( c m )}$ & Weight $\mathbf{( k g )}$ & BMI $\left(\mathbf{k g} / \mathbf{m}^{2}\right)$ \\
\hline Sleeping $(\mathrm{n}=22)$ & -0.153 & -0.343 & -0.191 & 0.071 \\
\hline Typing $(\mathrm{n}=37)$ & -0.248 & -0.274 & -0.292 & -0.229 \\
\hline Folding laundry $(\mathrm{n}=34)$ & -0.162 & 0.214 & $0.352^{*}$ & $0.362^{*}$ \\
\hline Dishwashing (n=32) & 0.060 & -0.272 & -0.253 & -0.182 \\
\hline Studying (n=18) & 0.370 & -0.281 & -0.511 & -0.578 \\
Mopping (n=35) & 0.125 & -0.159 & -0.216 & -0.204 \\
\hline Walking (n=33) & 0.078 & $-0.347^{*}$ & -0.306 & -0.212 \\
Stair climbing (n=23) & 0.236 & $-0.502^{*}$ & $-0.455^{*}$ & -0.295 \\
\hline Running (n=29) & 0.269 & -0.224 & -0.053 & 0.038 \\
\hline
\end{tabular}

BMI, body mass index; EE, energy expenditure; MET, metabolic equivalent. ${ }^{*} \mathrm{p}<0.05$.

study, the EEs of selected activities typical of Koreans were compared to those in the Compendium MET, and were similar for typing and mopping activities. Most of the values were different from those in the Compendium $(\mathrm{p}<0.01)$. These differences and the possible underlying reasons are discussed below.

The EE for sleeping of $1.24 \pm 0.43$ MET was higher than the Compendium value of 0.95 . Since sleeping requires the least $\mathrm{EE}$, the overestimation of the work required for sleeping could be due to lack of adaptation of the participants to the study conditions.

The Compendium MET for 'sitting, typing' is based on studies of sitting and writing [19] or that generated by typists working with typewriters [20]. In contrast, typing on a keyboard in this study represents the energy consumption due top use of a desktop computer. However, the measured MET value for typing was similar to that in the Compendium.

The EE for folding laundry was 1.6 MET, which was lower than that in the Compendium (2.0). The difference is likely due to the folding of laundry in a sitting position in this study, while that in the Compendium required other actions (i.e., hand washing, gathering clothes, putting clothes in and out of washer, and hanging). Of the 15 reference values used for averaging the Compendium MET, four included hand washing, which is performed less commonly than machine washing at present. One reference that included only folding laundry, however, involved greater work (a large box of clothes to fold) than the current study, and showed a higher mean MET of 2.3 [21].

The EE for dishwashing of $2.2 \pm 0.51$ MET was lower than that in the Compendium (2.5). However, considering the wide reference range and that the measured value falls within the range, the difference may not be significant.

The EE for studying activity was intriguing because the measured MET of 2.1 was higher than that in the Compendium MET (1.3 for self-study or 1.8 for in-class study $[22,23])$. The fact that the participants were required to understand the content of the text could have increased the level of work required. In addition, the Compendium MET was based on college students, who are accustomed to studying.

The floor-cleaning pattern has changed from scrubbing the floor on the hands and knees to standing using a mop. Thus, mopping in a standing position was selected as more representative of younger persons. The mean value of MET for mopping (2.7) was similar to that in the Compendium (2.5; $\mathrm{p}=0.067$ ). However, the Compendium MET value was the average of many studies involving only female subjects residing in rural areas of India, who have a low energy intake [24], or of the mean MET values of Chinese older ( $\geq 60$ years) and younger adults [25]. The mean MET of mopping in young adults (mean age, 21.6 years) in the Chinese study was 2.7 , which is comparable to our result.

The measured MET of 3.5 differed from that in the Compendium (3.0) for walking at 2.5 miles per hour $(\mathrm{mph})$ on a firm and level surface. However, since the Compendium value was the average of nine studies, the references were scrutinized in depth to identify the variables responsible for the difference. References included studies that did not report the walking speed [20,26-28], or used individual preferred speeds [29], or that involved 
only specific subgroups, such as indigenous females of the Northwest Amazon [30], female college students [31], females residing in rural regions [32] or Caucasians [33]. The average of studies that used a walking speed of 2.5 mph $[30,31,33]$ was $3.2 \mathrm{MET}$, which was similar to our finding.

The mean EE for stair climbing in this study was 6 MET, which is similar to the median of 4 and $8 \mathrm{MET}$, respectively, for slow and fast stair climbing in the Compendium. However, the slow and fast paces were not defined in the Compendium, complicating comparison with our data (average stair climbing speed, 2 to $2.5 \mathrm{~km} / \mathrm{hr}$ ). Moreover, the references included studies involving climbing down stairs [25] and of stair climbing with extra loads [21], and few described the height of the steps used.

The mean MET value for running at $5 \mathrm{mph}$ was 7.6, which was lower than that in the Compendium of 8.3. The mean age of references used to calculate the Compendium MET values were $24 \pm 3$ years [34], 21 \pm 2.4 years [35], while one study did not state the mean age of participants [36]. The mean age of $31 \pm 4.9$ years in this study was slightly older than that of the Compendium references.

Most of the differences between the Compendium and our MET values were related to variations in the activities and participants. Therefore, the EE established for various PAs requires further stratification according to physical stature and cultural background. The concept of the daily energy cost of an individual depending on their age, weight, height, and gender was developed over 100 years ago [37]. Likewise, the results of this study show a correlation of EE with weight and height. The EE for stair climbing was correlated with height $(\mathrm{r}=0.502, \mathrm{p}<0.05)$ and weight $(r=0.455, p<0.05)$; i.e., individuals of lower height and weight required a larger amount of energy for stair climbing. Also, the EE of folding laundry was positively correlated with BMI $(r=0.362, p=0.035)$.

The limitations of this study include the performance of activities of daily living in a laboratory in which an artificial household setting was prepared. The unfamiliar setting of each activity may have disrupted relaxation of the participants and could have led to overestimated oxygen consumption in activities with lower EE, such as studying. The application of a mask for collection of oxygen consumed could also have increased energy expenditure. As the MET measured by dividing work $\mathrm{VO}_{2}$ by 3.5 does not take into consideration the individual resting metabolic rate, the data do not reflect individual differences. Further study using established individual resting metabolic rates to compare with the MET values reported herein is thus warranted. Also, individual differences in the effort to perform the activity or in the status on the assessment day may have affected the result.

The duration of each activity (5 to 10 minutes) may be insufficient to induce physiological changes discernable by indirect calorimetry. However, maintaining a steady state whereby $\mathrm{VO}_{2}$ and $\mathrm{VCO}_{2}$ change by $<10 \%$ for 5 consecutive minutes is reported to be enough to complete the indirect calorimetry [38] and accuracy would not be affected over short measurement periods if a steady state was achieved [39]. The ICC values for walking, running and stair climbing suggest that the exercises were performed in a steady state in this study. Also, the influence of fatigue should be excluded in terms of the duration of activity measurement. As the current activity duration is unlikely to have caused fatigue, and was similar to that used in studies $[17,40]$, the activity duration likely did not exert a marked effect on the results.

Other confounding variables include the limited number of participants, who were neither randomized nor specified according to personal dietary or exercise traits. To document and standardize the sedentary lifestyle of participants, personalized activity log submission prior to enrollment could have been helpful. Moreover, other activities practical only in deskbound lifestyle or activities with more variable levels of MET need to be collected and stratified for future research especially in Korean. Indeed, estimation of leisure activities specific to Korea might facilitate PA guidance.

The study estimated the EE values in a young Korean population, which may be used as a standard reference for the activities of daily living in urban areas, especially for individuals in their 30s to 50s. The PA values could be used to formulate guidelines for the general population and those with comorbidities or physical conditions in Korea.

\section{CONFLICT OF INTEREST}

No potential conflict of interest relevant to this article was reported. 


\section{ACKNOWLEDGMENTS}

This study was supported by a grant from the Korea Ministry of Trade, Industry and Energy (No. 10044381). The researchers thank all participants who volunteered and performed the tasks enthusiastically.

\section{REFERENCES}

1. Charansonney OL. Physical activity and aging: a lifelong story. Discov Med 2011;12:177-85.

2. Kokkinos P, Myers J. Exercise and physical activity: clinical outcomes and applications. Circulation 2010;122:1637-48.

3. Schmid D, Leitzmann MF. Association between physical activity and mortality among breast cancer and colorectal cancer survivors: a systematic review and meta-analysis. Ann Oncol 2014;25:1293-311.

4. Caspersen CJ, Powell KE, Christenson GM. Physical activity, exercise, and physical fitness: definitions and distinctions for health-related research. Public Health Rep 1985;100:126-31.

5. Schutz Y, Weinsier RL, Hunter GR. Assessment of freeliving physical activity in humans: an overview of currently available and proposed new measures. Obes Res 2001;9:368-79.

6. Byrne NM, Hills AP, Hunter GR, Weinsier RL, Schutz Y. Metabolic equivalent: one size does not fit all. J Appl Physiol (1985) 2005;99:1112-9.

7. Jette M, Sidney K, Blumchen G. Metabolic equivalents (METS) in exercise testing, exercise prescription, and evaluation of functional capacity. Clin Cardiol 1990;13:555-65.

8. World Health Organization. Energy and protein requirements: report of a Joint FAO/WHO/UNU Expert Consultation. Geneva: World Health Organization; 1985.

9. Ainsworth BE, Haskell WL, Leon AS, Jacobs DR Jr, Montoye HJ, Sallis JF, et al. Compendium of physical activities: classification of energy costs of human physical activities. Med Sci Sports Exerc 1993;25:7180.

10. Ainsworth BE, Haskell WL, Herrmann SD, Meckes N, Bassett DR Jr, Tudor-Locke C, et al. 2011 Compendium of Physical Activities: a second update of codes and MET values. Med Sci Sports Exerc 2011;43:1575-
81.

11. Korea Ministry of Health and Welfare. The physical activity guide for Koreans. Sejong: Ministry of Health and Welfare; 2013.

12. Saffer H, Dave D, Grossman M, Leung LA. Racial, ethnic, and gender differences in physical activity. J Hum Cap 2013;7:378-410.

13. Food and Agriculture Organization of the United Nations; United Nations University; World Health Organization. Human energy requirements: report of a Joint FAO/WHO/UNU Expert Consultation. Rome: Food and Agriculture Organization of the United Nations; 2004.

14. Lee IM, Skerrett PJ. Physical activity and all-cause mortality: what is the dose-response relation? Med Sci Sports Exerc 2001;33(6 Suppl):S459-71.

15. Ainsworth BE, Haskell WL, Whitt MC, Irwin ML, Swartz AM, Strath SJ, et al. Compendium of physical activities: an update of activity codes and MET intensities. Med Sci Sports Exerc 2000;32(9 Suppl):S498-504.

16. Waters RL, Mulroy S. The energy expenditure of normal and pathologic gait. Gait Posture 1999;9:207-31.

17. Schrack JA, Simonsick EM, Ferrucci L. Comparison of the Cosmed K4b(2) portable metabolic system in measuring steady-state walking energy expenditure. PLoS One 2010;5:e9292.

18. K4b2 [Internet]. Rome: COSMED; c2016 [cited 2016 Jul 1]. Available from: http://www.cosmed.it/en/ products/cardio-pulmonary-exercise-testing/k4-b2mobile-cpet.

19. Passmore R, Durnin JV. Human energy expenditure. Physiol Rev 1955;35:801-40.

20. de Guzman PE, Cabrera JP, Basconcillo RO, Gaurano AL, Yuchingtat GP, Tan RM, et al. A study of the energy expenditure, dietary intake and pattern of daily activity among various occupational groups. V: Clerktypist. Philippine J Nutr 1978;31:147-56.

21. Kozey SL, Lyden K, Howe CA, Staudenmayer JW, Freedson PS. Accelerometer output and MET values of common physical activities. Med Sci Sports Exerc 2010;42:1776-84.

22. Bandyopadhyay B, Chattopadhyay H. Energy metabolism in male college students. Indian J Med Res 1980;71:961-9.

23. Li J, Yan WY. The energy expenditure and nutritional status of college students. I: The energy cost and the 
total energy expenditure per day. Biomed Environ Sci 1991;4:295-303.

24. Bains K, Kaur B, Mann SK. Measurement of energy cost of selected household and farm activities performed by rural women. Food Nutr Bull 2002;23:2749.

25. Yue AS, Woo J, Ip KW, Sum CM, Kwok T, Hui SS. Effect of age and gender on energy expenditure in common activities of daily living in a Chinese population. Disabil Rehabil 2007;29:91-6.

26. de Guzman PE, Recto RC, Cabrera JP, Basconcillo RO, Gaurano AL, Yuchingtat GP, et al. A study of the energy expenditure, dietary intake and pattern of daily activity among various occupational groups. VI: Textilemill workers. Philippine J Nutr 1979;32:134-48.

27. de Guzman PE, Cabera JP, Yuchingtat GP, Abanto ZU, Gaurano AL. A study of energy expenditure, dietatry intake and pattern of daily activity among various occupational groups. II: Laguna Rice farmers. Philippine J Nutr 1984;37:163-74.

28. Brun T, Bleiberg F, Goihman S. Energy expenditure of male farmers in dry and rainy seasons in Upper-Volta. Br J Nutr 1981;45:67-75.

29. Dal U, Erdogan T, Resitoglu B, Beydagi H. Determination of preferred walking speed on treadmill may lead to high oxygen cost on treadmill walking. Gait Posture 2010;31:366-9.

30. Dufour DL. The time and energy expenditure of indigenous women horticulturalists in the northwest Amazon. Am J Phys Anthropol 1984;65:37-46.

31. Anjos LA, Wahrlich V, Bossan FM, Salies MN, Silva PB. Energy expenditure of walking at different intensities in Brazilian college women. Clin Nutr 2008;27:121-5.

32. Torun B, McGuire J, Mendoza RD. Energy cost of activities and tasks of women from a rural region of Guatemala. Nutr Res 1982;2:127-36.

33. Barkley JE, Penko A. Physiologic responses, perceived exertion, and hedonics of playing a physical interactive video game relative to a sedentary alternative and treadmill walking in adults. J Exerc Physiol Online 2009;12:12-22.

34. Sherman WM, Morris DM, Kirby TE, Petosa RA, Smith BA, Frid DJ, et al. Evaluation of a commercial accelerometer (Tritrac-R3 D) to measure energy expenditure during ambulation. Int J Sports Med 1998;19:43-7.

35. Sentija D, Markovic G. The relationship between gait transition speed and the aerobic thresholds for walking and running. Int J Sports Med 2009;30:795-801.

36. Haymes EM, Byrnes WC. Walking and running energy expenditure estimated by Caltrac and indirect calorimetry. Med Sci Sports Exerc 1993;25:1365-9.

37. Harris JA, Benedict FG. A Biometric Study of Human Basal Metabolism. Proc Natl Acad Sci U S A 1918;4:370-3.

38. McClave SA, Spain DA, Skolnick JL, Lowen CC, Kieber MJ, Wickerham PS, et al. Achievement of steady state optimizes results when performing indirect calorimetry. JPEN J Parenter Enteral Nutr 2003;27:16-20.

39. Reeves MM, Davies PS, Bauer J, Battistutta D. Reducing the time period of steady state does not affect the accuracy of energy expenditure measurements by indirect calorimetry. J Appl Physiol (1985) 2004;97:1304.

40. Bassett DR Jr, Ainsworth BE, Swartz AM, Strath SJ, O'Brien WL, King GA. Validity of four motion sensors in measuring moderate intensity physical activity. Med Sci Sports Exerc 2000;32(9 Suppl):S471-80. 